\title{
Determination of Carcinogenic and Allergenic Dyestuffs in Toys by LC Coupled to UV/Vis Spectrometry and Tandem Mass Spectrometry
}

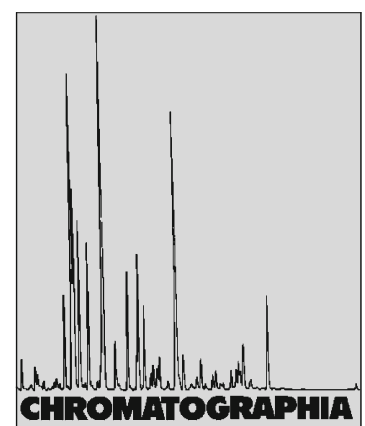

2010, 72, 85-93

\author{
Qiang $M a^{1,2, 凶}$, Hua Bai ${ }^{1}$, Qing Zhang ${ }^{1}$, Wei $\mathrm{Ma}^{3,4}$, Haiwei $\mathrm{Xi}^{1}$, Xin Zhou ${ }^{1}$, Chao Wang ${ }^{1}$ \\ ${ }^{1}$ Chinese Academy of Inspection and Quarantine, Beijing 100123, China; E-Mail: maqiang1 129@yahoo.com.cn \\ 2 State Key Laboratory of Environmental Chemistry and Ecotoxicology, Research Center for Eco-Environmental Sciences, Chinese Academy of \\ Sciences, Beijing 100085, China \\ ${ }^{3}$ China Agriculture University, Beijing 100083, China \\ ${ }^{4}$ Heilongjiang Entry-Exit Inspection and Quarantine Bureau, Harbin 150086, China
}

\begin{abstract}
A comprehensive analytical method based on LC coupled with ultraviolet-visible spectrometric detection and tandem mass spectrometry has been developed for the determination of sixteen carcinogenic and allergenic dyestuffs in toys. Various toy samples, including textiles, leathers, woods, paper, aqueous liquids, solid toy materials such as crayons, modeling or play clay, balloons and temporary tattoos were ultrasonically extracted with ethanol. Quantitative analysis was carried out after chromatographic separation with a mobile phase of acetonitrile-tetrahydrofuran-citrate buffered tetrabutylammonium hydroxide mixture under gradient elution. The mean recoveries at three spiked levels were between 88.6 and 104.7, with the relative standard deviations from 1.6 to $6.7 \%$. The intra-day reproducibility ranged from 1.7 to $3.9 \%$ and inter-day reproducibility ranged from 3.0 to $5.8 \%$. The identities of the dyestuffs were further verified by LC-tandem mass spectrometry. The method was successfully applied to the investigation of different toy components.
\end{abstract}

\section{Keywords}

Column liquid chromatography

Ultraviolet-visible spectrometric detection

Tandem mass spectrometry

Carcinogenic and allergenic dyestuffs

Toys

\section{Introduction}

With the worldwide increasing awareness of risk precautions and health protection, the issue of toy safety has become the focus of public attention. Chemicals with carcinogenic, mutagenic or toxic properties in toy components may be ingested or absorbed subcutaneously and bring detrimental effects to health. Dyestuffs classified according to how they are used in the dyeing process, include basic dyes, acid dyes, solvent dyes and disperse dyes. These different categories possess different dyeing mechanisms, chemical structures and properties. It has been confirmed that many dyestuffs in toys, including Acid Red 26, Basic Red 9, Disperse Blue 1, Acid Violet 49, Disperse Blue 3, Solvent Yellow 1, Disperse Blue 106, Disperse Orange 3, Disperse Yellow 3, Basic Violet 1, Basic Violet 3, Disperse Red 1, Solvent Yellow 3, Disperse Blue 124, Solvent Yellow 2 and Disperse Orange 37 are carcinogenic or have sensitizing effects [1]. Compared with most azo 
dyes, which generate carcinogenic aromatic amines due to the cleavage of the azo bond when they are reduced, the dyestuffs listed above do not undergo a reductive reaction, but may cause cancer if people are exposed to them for a long time. Many countries and international organizations have laid down strict safety regulations and standards to limit the potential danger originating from hazardous chemical substances in toys and ensure their safety. According to the EN 71 Part 9-11 toy safety standards formulated by the European Committee for Standardization, the sixteen carcinogenic and allergenic dyestuffs involved in this study should not be used in toy products [1]. The Oeko-Tex Standard 1000 [2] as well as European Union Commission Decision 2009/567/EC [3] also lists Basic Violet 3, Disperse Blue 3, Acid Red 26, Disperse Blue 106, Disperse Yellow 3, Disperse Red 1, Basic Red 9, Basic Violet 1, Disperse Blue 1, Disperse Blue 124, Disperse Orange 3 and Disperse Orange 37 as prohibited substances.

The currently available analytical methods for the detection of dyestuffs are normally aimed at certain limited categories of dyestuffs, e.g., LC [4, 5] or $\mathrm{CE}$ [6] for the analysis of basic dyestuffs; LC or ion-interaction LC [7] for acid dyestuffs; LC coupled with mass spectrometry (LC-MS) [8] or LC for solvent dyestuffs [9]; LC, LC-MS [10] and ultraviolet-visible spectrophotometry (UV/Vis) [11] for disperse dyestuffs. In view of the diversity and the number of dyestuffs, there is an urgent need to establish a unified, accurate and effective analytical method to realize the rapid and comprehensive screening of carcinogenic and allergenic dyestuffs in toys. A first attempt was described in EN 71-11, however, the method is not wholly satisfactory due to limited instrumental information, and suboptimal conditions.

This paper describes a comprehensive method based on LC coupled with ultraviolet-visible spectrometry and tandem mass spectrometry for the detection and analysis of sixteen carcinogenic and allergenic dyestuffs, including Acid Red 26, Basic Red 9, Disperse Blue 1, Acid Violet 49, Disperse Blue 3, Solvent Yellow 1, Disperse Blue 106,
Disperse Orange 3, Disperse Yellow 3, Basic Violet 1, Basic Violet 3, Disperse Red 1, Solvent Yellow 3, Disperse Blue 124, Solvent Yellow 2 and Disperse Orange 37 in toys. Due to its simplicity, specificity and sensitivity, the method can meet the requirements for the inspection and quality control of toy products.

\section{Experimental}

\section{Reagents and Materials}

Basic Violet 3 (80\%), Acid Violet 49 (96\%), Disperse Blue 3 (20\%), Acid Red 26 (84\%), Basic Red 9 (95\%), Basic Violet 1 (30\%), Disperse Blue 124 (70\%) and Solvent Yellow 2 (95\%) were obtained from Dr. Ehrenstorfer (Augsburg, Germany). Disperse Blue 106 (95\%), Disperse Yellow $3(30 \%)$, Disperse Red $1(95 \%)$, Disperse Blue 1 (30\%), Solvent Yellow $1(99 \%)$ and Disperse Orange 37 $(95 \%)$ were purchased from SigmaAldrich (St Louis, MO, USA). Disperse Orange $3(95 \%)$ and Solvent Yellow 3 (99\%) were from Acros (Geel, Belgium). All the dyestuff reference standards utilized in the current research were of the highest purity commercially available.

All solvents (methanol, tetrahydrofuran, acetonitrile, ethanol) were LC grade (Fisher Scientific, Pittsburgh, PA, USA). Tetrabutylammonium hydroxide solution $(40 \%, v / v)$ and citric acid were purchased from Dikma (Lake Forest, CA, USA). Ammonium hydroxide of analytical purity was from Beijing Chemical Company (Beijing, China). Ultra-pure water was obtained using a Milli-Q Ultrapure system (Millipore, Bedford, MA, USA).

\section{Preparation of Standard Solutions}

Stock standard solutions of individual dyestuffs at a concentration of 1,000 $\mathrm{mg} \mathrm{L}^{-1}$ each were prepared in methanol. When preparing stock solutions of each dyestuff, purity values were taken into account. Two groups of working standard solutions (Group 1: Basic Violet 3, Acid Violet 49, Disperse Blue 3, Acid Red 26, Disperse Blue 106, Disperse Yellow 3 and Disperse Red 1; Group 2: Basic Red 9, Basic Violet 1, Disperse Blue 1, Disperse Blue 124, Solvent Yellow 1, Disperse Orange 3, Solvent Yellow 3, Solvent Yellow 2 and Disperse Orange 37) containing $50 \mathrm{mg} \mathrm{L}^{-1}$ of each dyestuff were prepared by appropriate dilution of the stock standard solutions with methanol.

\section{Sample Preparation}

Various toy components or materials (textiles, leathers, woods, paper, aqueous liquids, solid toy materials such as crayons, modeling or play clay, balloons, temporary tattoos, etc.) were collected separately. Representative test portions were taken from accessible parts of the toy samples and cut into pieces with a size below $3 \mathrm{~mm} \times 3 \mathrm{~mm}$ and then homogenised for later use.

Aliquots $(0.500 \mathrm{~g})$ of different samples were weighed and transferred into a 50-mL conical flask with cover. $15 \mathrm{~mL}$ of ethanol were added to the flask, vortex-mixed for $1 \mathrm{~min}$, and then extracted in an ultrasonic bath at $42 \mathrm{kHz}$ for $15 \mathrm{~min}$. The extract was transferred into a $50-\mathrm{mL}$ flask, and the residue was extracted again with another $15 \mathrm{~mL}$ of ethanol. The extracts were combined, evaporated, dried under a gentle stream of nitrogen and reconstituted with $1 \mathrm{~mL}$ methanol and finally filtered through a $0.20 \mu \mathrm{m}$ membrane filter unit prior to further instrumental analysis.

\section{Liquid Chromatography- Ultraviolet-Visible Spectrometry}

Chromatography was performed on a 1200 system (Agilent Technologies, Palo Alto, CA, USA) equipped with online degasser, quaternary pump, autosampler with $100 \mu \mathrm{L}$ injection loop, thermostated compartment, and diode array detector. The separation was performed with an Agilent $5 \mu \mathrm{m}$ Zorbax Extend $\mathrm{C}_{18}$ column $(250 \mathrm{~mm} \times 4.6 \mathrm{~mm}$, $)$. A linear gradient of mobile phase A (15 mM citrate$20 \mathrm{mM}$ tetrabutylammonium hydroxide solution, adjusted to $\mathrm{pH} 9.0$ with ammonium hydroxide), mobile phase $\mathrm{B}$ 
(tetrahydrofuran) and mobile phase $\mathrm{C}$ (acetonitrile) was applied (Table 1). A

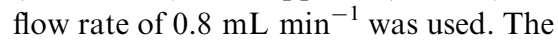
column temperature was set at $25^{\circ} \mathrm{C}$, and the injection volume was $20 \mu \mathrm{L}$. The sixteen dyestuffs were classified into two groups, as described in the section of preparation of standard solutions. Each dyestuff was detected and quantified at its respective maximum ultraviolet-visible absorption wavelength for optimum sensitivity (Table 2). The chromatograms of the dyestuffs in Group 1 and Group 2 were shown in Fig. 1.

\section{Liquid Chromatography- Tandem Mass Spectrometry}

The LC-tandem mass spectrometry system consisted of an Alliance 2695 LC system (Waters, Milford, MA, USA) equipped with quaternary gradient pump, autosampler with $100 \mu \mathrm{L}$ injection loop and a Quattro micro atmospheric pressure ionization (API) tandem mass spectrometer (Micromass, Manchester, UK) equipped with electrospray ionization (ESI) source. Analytes were separated on a Waters $3.5 \mu \mathrm{m}$ XBridge $\mathrm{C}_{18} \quad$ column $\quad(150 \mathrm{~mm} \times$ $2.1 \mathrm{~mm})$. The mobile phase consisted of A (acetonitrile) and $\mathrm{B}\left(5 \mathrm{mmol} \mathrm{L}^{-1}\right.$ ammonium acetate, adjusted to $\mathrm{pH}$ 5.0). The acetonitrile was linearly increased from 10 to $28 \%$ in $1 \mathrm{~min}$, then changed to $40 \%$ in $3 \mathrm{~min}$ and increased to $95 \%$ in $5 \mathrm{~min}$ and held for $3 \mathrm{~min}$, finally brought back to $10 \%$ in $2 \mathrm{~min}$. The flow rate was $0.3 \mathrm{~mL} \mathrm{~min}^{-1}$ and the column oven was kept at $30{ }^{\circ} \mathrm{C}$.

MS-MS data were acquired in the positive ion mode with typical ion source parameters set as follows: ESI capillary voltage $3.5 \mathrm{kV}$, extractor voltage $1.0 \mathrm{~V}$, radiofrequency (RF) lens voltage $0.5 \mathrm{~V}$, source block temperature $120{ }^{\circ} \mathrm{C}$, desolvation temperature $350{ }^{\circ} \mathrm{C}$, nitrogen desolvation gas flow rate $600 \mathrm{~L} \mathrm{~h}^{-1}$, cone gas flow rate $50 \mathrm{~L} \mathrm{~h}^{-1}$, ion energy 1 and 2 both set at $0.5 \mathrm{~V}$, and multiplier voltage $650 \mathrm{~V}$. During tandem mass spectrometric analysis, ultra-high-purity argon was used as the collision gas, and the pressure of the collision chamber was maintained at $3.2 \times 10^{-3}$ mbar.
Table 1. Gradient elution program of 16 dyestuffs for the LC-DAD method

\begin{tabular}{|rlll|}
\hline Time (min) & Mobile phase A (\%) & Mobile phase B (\%) & Mobile phase C (\%) \\
\hline 0.00 & 75 & 10 & 15 \\
5.00 & 75 & 10 & 15 \\
17.00 & 55 & 20 & 25 \\
35.00 & 10 & 35 & 55 \\
40.00 & 75 & 10 & 15 \\
\hline
\end{tabular}

Table 2. Detection wavelength, precursor ions, product ions, cone voltages and collision energies used for detection of 16 dyestuffs

\begin{tabular}{|c|c|c|c|c|c|}
\hline Dyestuffs & $\begin{array}{l}\text { Detection } \\
\text { wavelength (nm) }\end{array}$ & $\begin{array}{l}\text { Precursor } \\
\text { ion }(m / z)\end{array}$ & $\begin{array}{l}\text { Cone } \\
\text { voltage }(\mathrm{V})\end{array}$ & $\begin{array}{l}\text { Product } \\
\text { ion }(m / z)\end{array}$ & $\begin{array}{l}\text { Collision } \\
\text { energy }(\mathrm{eV})\end{array}$ \\
\hline Basic Violet 3 & 600 & 372.2 & 40 & $\begin{array}{l}356.2^{\mathrm{a}} \\
251.1\end{array}$ & $\begin{array}{l}37 \\
35\end{array}$ \\
\hline Acid Violet 49 & 600 & 713.4 & 60 & $\begin{array}{l}527.3^{\mathrm{a}} \\
341.2\end{array}$ & $\begin{array}{l}50 \\
60\end{array}$ \\
\hline Disperse Blue 3 & 640 & 297.1 & 25 & $\begin{array}{l}252.0^{\mathrm{a}} \\
235.1\end{array}$ & $\begin{array}{l}18 \\
30\end{array}$ \\
\hline Acid Red 26 & 500 & 437.1 & 30 & $\begin{array}{l}355.0^{\mathrm{a}} \\
327.0\end{array}$ & $\begin{array}{l}18 \\
25\end{array}$ \\
\hline Disperse Blue 106 & 600 & 336.0 & 25 & $\begin{array}{l}178.1^{\mathrm{a}} \\
196.2^{2}\end{array}$ & $\begin{array}{l}16 \\
15\end{array}$ \\
\hline Disperse Yellow 3 & 360 & 270.1 & 20 & $\begin{array}{l}106.9^{\mathrm{a}} \\
150.0\end{array}$ & $\begin{array}{l}20 \\
17\end{array}$ \\
\hline Disperse Red 1 & 500 & 315.1 & 30 & $\begin{array}{l}134.0^{\mathrm{a}} \\
255.1\end{array}$ & $\begin{array}{l}23 \\
27\end{array}$ \\
\hline Basic Red 9 & 540 & 288.2 & 40 & $\begin{array}{l}195.1^{\mathrm{a}} \\
168.1\end{array}$ & $\begin{array}{l}30 \\
35\end{array}$ \\
\hline Basic Violet 1 & 600 & 358.2 & 40 & $\begin{array}{l}342.2^{\mathrm{a}} \\
237.1\end{array}$ & $\begin{array}{l}35 \\
32\end{array}$ \\
\hline Disperse Blue 1 & 640 & 269.0 & 40 & $\begin{array}{l}106.9^{\mathrm{a}} \\
161.0\end{array}$ & $\begin{array}{l}35 \\
23\end{array}$ \\
\hline Disperse Blue 124 & 600 & 378.2 & 28 & $\begin{array}{l}160.1^{\mathrm{a}} \\
220.1^{1}\end{array}$ & $\begin{array}{l}20 \\
15\end{array}$ \\
\hline Solvent Yellow 1 & 390 & 198.1 & 25 & $\begin{array}{l}152.0^{\mathrm{a}} \\
124.9\end{array}$ & $\begin{array}{l}18 \\
22\end{array}$ \\
\hline Disperse Orange 3 & 440 & 243.0 & 27 & $\begin{array}{l}139.9^{\mathrm{a}} \\
121.9^{2}\end{array}$ & $\begin{array}{l}15 \\
17\end{array}$ \\
\hline Solvent Yellow 3 & 390 & 226.1 & 26 & $\begin{array}{l}106.9^{\mathrm{a}} \\
120.9\end{array}$ & $\begin{array}{l}25 \\
23\end{array}$ \\
\hline Solvent Yellow 2 & 420 & 226.1 & 26 & $\begin{array}{l}120.9^{\mathrm{a}} \\
134.0\end{array}$ & $\begin{array}{l}30 \\
20\end{array}$ \\
\hline Disperse Orange 37 & 440 & 394.1 & 30 & $\begin{array}{l}133.0^{\mathrm{a}} \\
353.0\end{array}$ & $\begin{array}{l}35 \\
20\end{array}$ \\
\hline
\end{tabular}

${ }^{\text {a }}$ Quantification ion

Qualitative and quantitative analysis for the sixteen dyestuffs were performed in multiple reaction monitoring (MRM) mode (Fig. 2). The precursor ion, product ion, cone voltage and collision energy for each dyestuff are shown in Table 2. One precursor ion and two corresponding product ions were selected to achieve four identification points complying with the European Union Directive 2002/657/EC [12]. The LC-MS-MS protocol was adopted to confirm the identity of the analytes.

\section{Results and Discussion}

\section{Optimization of Liquid Chromatography}

In the ion-pair chromatographic mode for the analysis of dyestuffs, the positively charged ion-pair reagent (tetrabutylammonium hydroxide) was added to the mobile phase and attached to the stationary phase by hydrophobic interaction with the alkyl moiety, causing a strong attraction of the negatively 
(a)
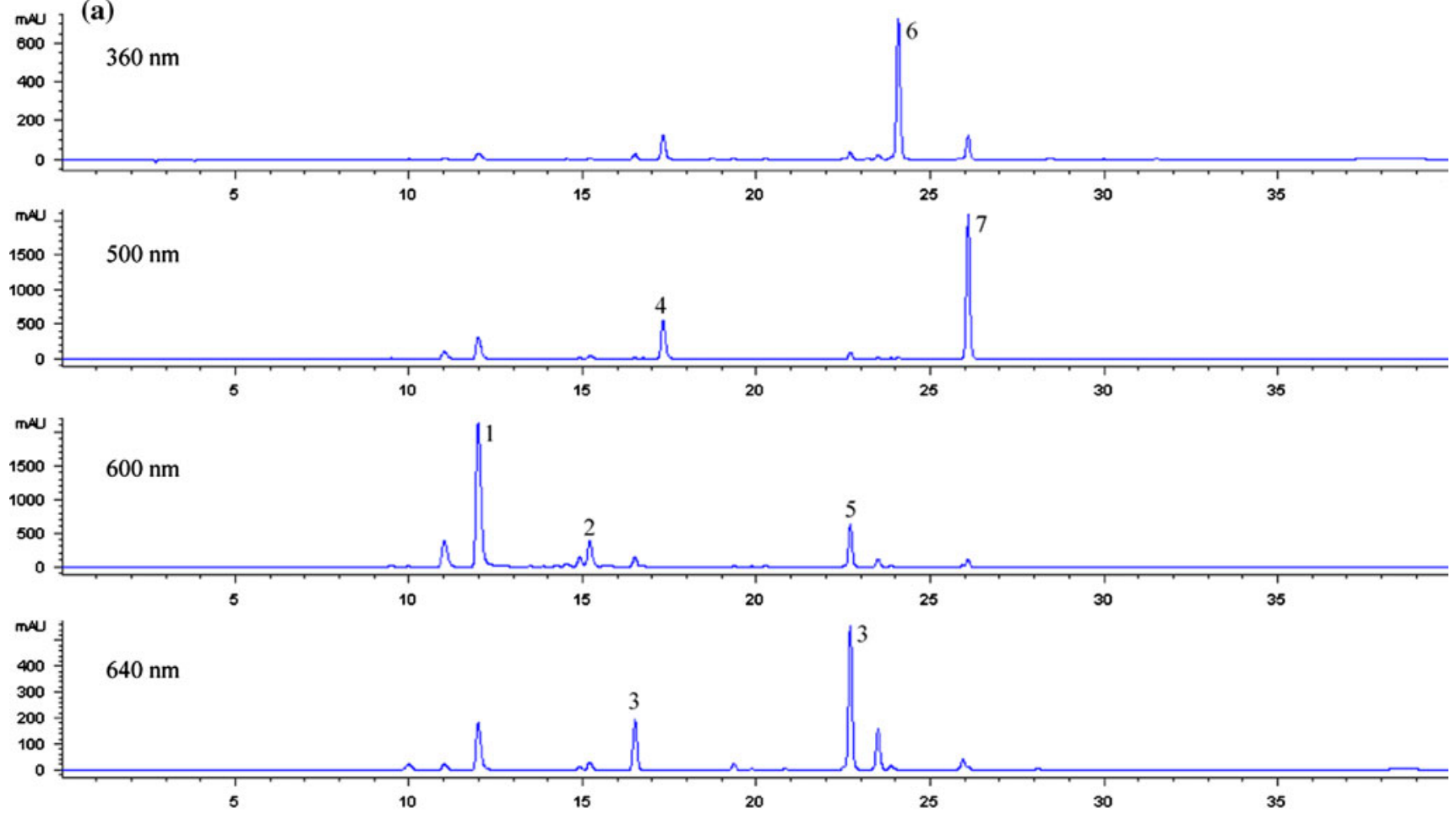

(b)
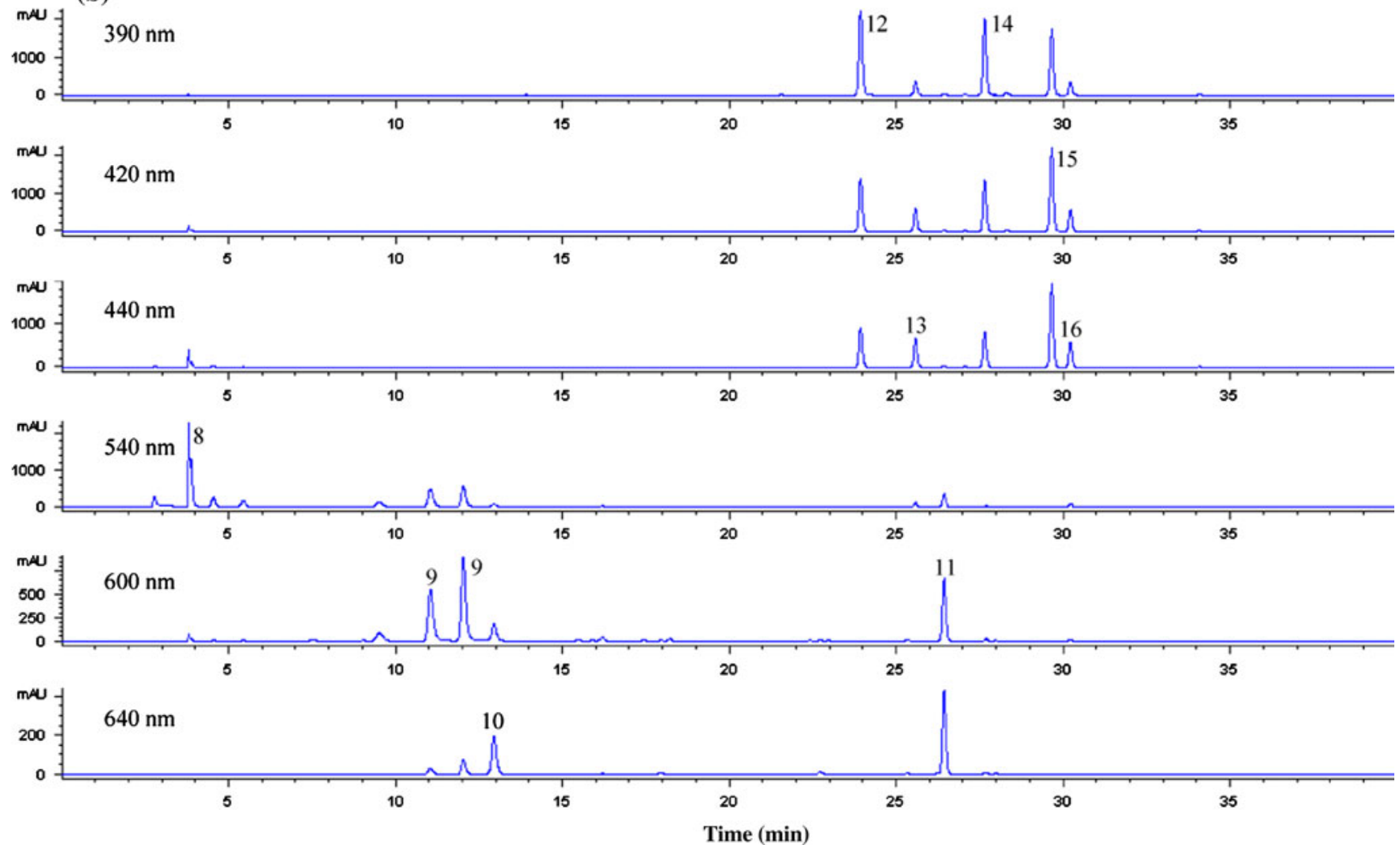

Fig. 1. a Chromatogram of the dyestuffs in Group 1 of LC-DAD method. $1=$ Basic Violet 3, $2=$ Acid Violet $49,3=$ Disperse Blue 3 , $4=$ Acid Red 26, 5 = Disperse Blue 106, 6= Disperse Yellow 3, $7=$ Disperse Red 1; b Chromatogram of the dyestuffs in Group 2 of LC-DAD method. 8 = Basic Red 9, $9=$ Basic Violet 1, $10=$ Disperse Blue 1, $11=$ Disperse Blue 124, $12=$ Solvent Yellow 1, $13=$ Disperse Orange 3 , $14=$ Solvent Yellow 3, $15=$ Solvent Yellow 2, $16=$ Disperse Orange 37 
charged dyestuffs. A series of chromatographic parameters, such as ionpair reagent type and concentration, $\mathrm{pH}$ value, buffer type and concentration, solvent type and strength and column temperature were evaluated. In view of the acid property of most dyestuffs, several commonly-used positive ion-pair reagents, i.e., tetrabutylammonium hydroxide, tetrabutylammonium bromide and tetrabutylammonium chloride were investigated. Tetrabutylammonium hydroxide was shown to have a relatively higher efficiency in decreasing solute silanophilic interactions and relatively shorter column equilibration time due to its moderate hydrophobicity. A tetrabutylammonium hydroxide concentration of $20 \mathrm{mM}$ was chosen in the mobile phase, according to a retention versus reagent concentration curve, to achieve a significant retention of the analyte on the column. It is important to maintain a constant $25{ }^{\circ} \mathrm{C}$ column temperature with the thermostated compartment to stabilize several equilibrium processes, such as sample retention by ion-exchange, sorption of the ion-pair reagent on the chromatographic column, reversedphase processes, etc. When ion-pair chromatography was used, the column was conditioned by passing the mobile phase through it for at least $2 \mathrm{~h}$ at a flow-rate of $0.8 \mathrm{~mL} \mathrm{~min}^{-1}$.

The sixteen dyestuffs have a wide range of octanol/water partition coefficients $\left(\log K_{\text {ow }}\right.$; calculated by EPI Suite v4.00 software of EPA), ranging from -0.83 to 4.58 , indicating the disparity of their polarity. The sixteen dyestuffs involved in the current study include acid, basic as well as disperse dyestuffs, with chemical structures covering azo, triacrylmethane, anthraquinone and heterocyclic categories. To achieve the satisfactory chromatographic separation of all these different dyestuffs in an acceptable period of time, a gradient elution program was adopted and carefully optimized. According to their respective properties and actual chromatographic behavior, the sixteen dyestuffs were re-classified into two groups for their analysis and determination. Based on the above liquid chromatographic optimization, better chromatographic separation of the sixteen

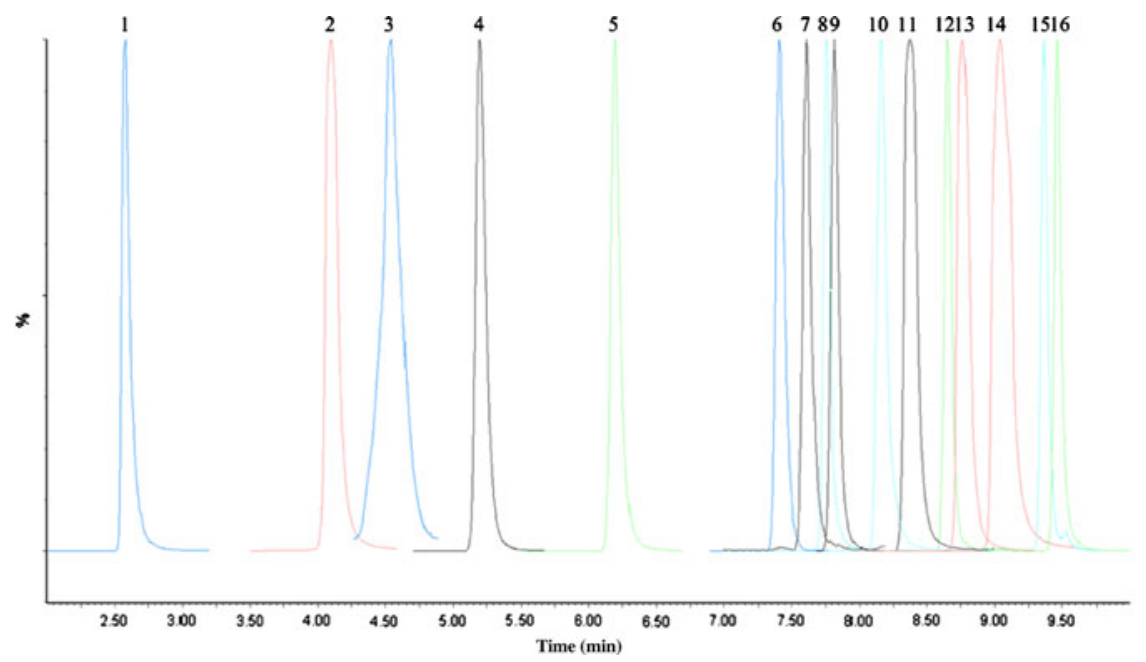

Fig. 2. Multiple reaction monitoring chromatogram of 16 carcinogenic and allergenic dyestuffs. $1=$ Acid Red 26, $2=$ Basic Red 9, $3=$ Disperse Blue 1, $4=$ Acid Violet 49, $5=$ Disperse Blue 3, $6=$ Disperse Blue 106, $7=$ Solvent Yellow 1, $8=$ Disperse Orange 3, $9=$ Disperse Yellow 3, $10=$ Disperse Red 1, 11 = Basic Violet 1, 12 = Disperse Blue 124, $13=$ Solvent Yellow 3, $14=$ Basic Violet 3, $15=$ Disperse Orange 37, $16=$ Solvent Yellow 2

dyestuffs was obtained compared with that of EN 71-11.

\section{Optimization of Mass Spectrometry}

Full scans in the positive as well as negative ionization modes were initially applied to identify the precursor ions by direct flow injection $[(\mathrm{M}-\mathrm{nNa})+$ $(\mathrm{n}+1) \mathrm{H}]^{+}$, in which $\mathrm{n}$ represented the number of sodium atoms, for sodiumbearing dyestuffs, such as Acid Red 26, Acid Violet 49, $[\mathrm{M}-\mathrm{Cl}+\mathrm{H}]^{+}$for chlorine-bearing dyestuffs, such as Basic Red 9, Basic Violet 1, Basic Violet 3, and $[\mathrm{M}+\mathrm{H}]^{+}$for other dyestuffs, were found to be the most abundant mass-to-charge $(\mathrm{m} / \mathrm{z})$ ions in the positive ionization mode. These pseudo-molecular ions were selected as the precursor ions for further collision-induced dissociation fragmentation to investigate the resulting product ions. The MS spectra of the sixteen carcinogenic and allergenic dyestuffs are shown in Fig. 3.

Based on these precursor ions and the corresponding product ions, a series of mass spectrometric parameters, including ESI capillary voltage, cone voltage, extractor voltage, RF lens voltage, collision energy, source temperature, desolvation gas temperature and flow, cone gas flow, etc., were optimized. For the detection by LC-MS-MS, identification occurs with the retention time and diagnostic ions consisting of two daughter ions for each dyestuff. For confirmatory purpose, a comparison with quality control samples was made using acceptable deviations of $\pm 2.5 \%$ for retention time and of $\pm 20 \%$ for the ionic relative abundance as described in the European Union Commission Decision 2002/657/EC laying down performance criteria of analytical methods. The precursor ion, product ion, cone voltage and collision energy of each dyestuff for MRM acquisition mode are shown in Table 2. Two transitions were selected for identification but only one used for quantification.

Since the mobile phase composition containing non-volatile buffer as well as column configuration involved in LC analysis does not fit LC-MS-MS, the chromatographic conditions for LCMS-MS were re-optimized. The ESI ionization occurs in the solution state, hence, the mobile phase and its additives may affect the sensitivity of the analytes. To achieve the best sensitivity for the dyestuffs, mobile phases consisting of water with different organic solvents, i.e., methanol, acetonitrile and tetrahy- 


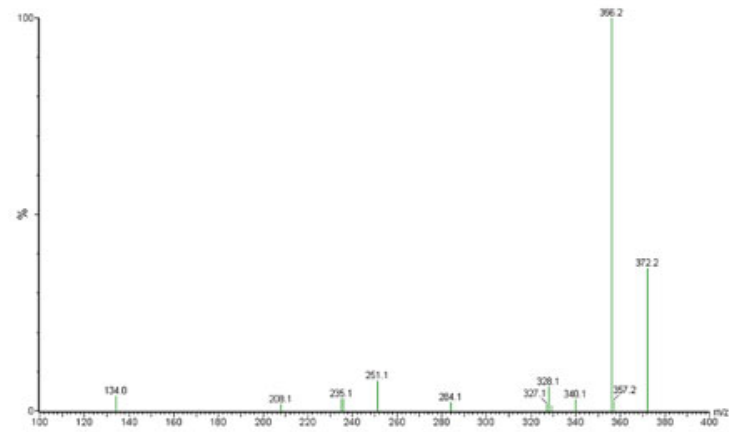

(a) Basic Violet 3

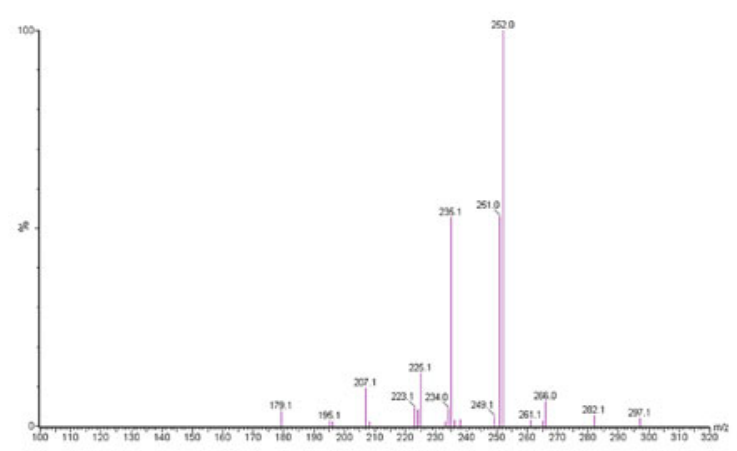

(c) Disperse Blue 3

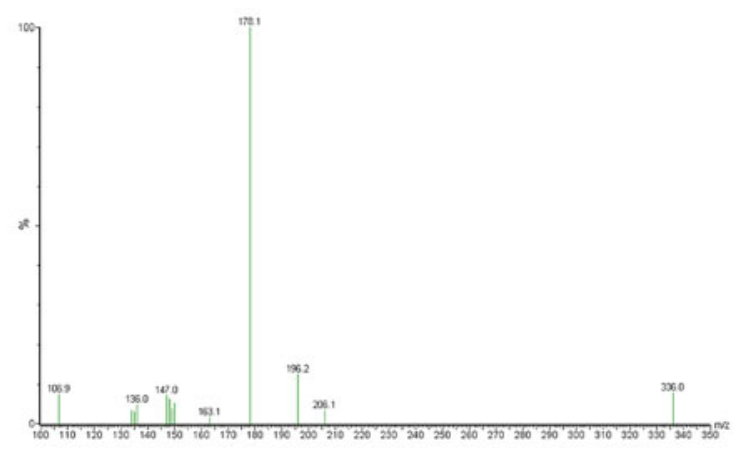

(e) Disperse Blue 106

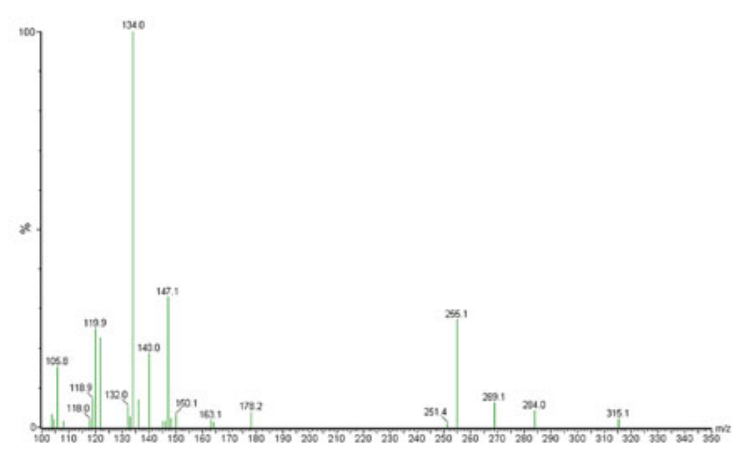

(g) Disperse Red 1

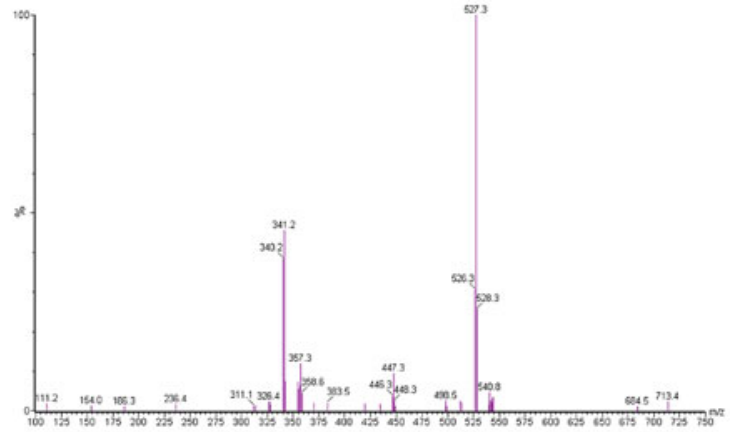

(b) Acid Violet 49

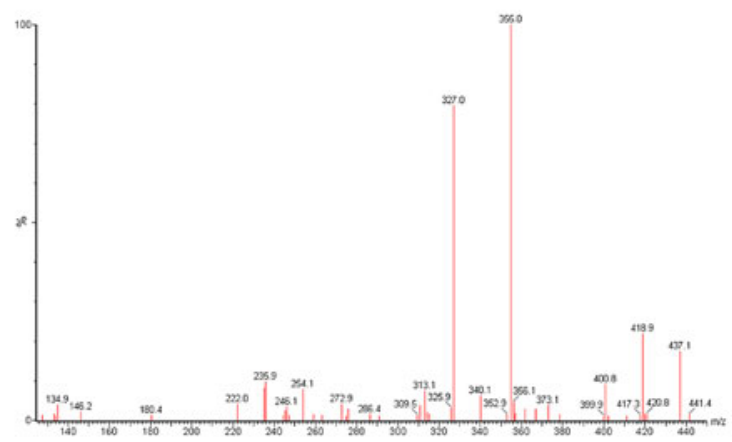

(d) Acid Red 26

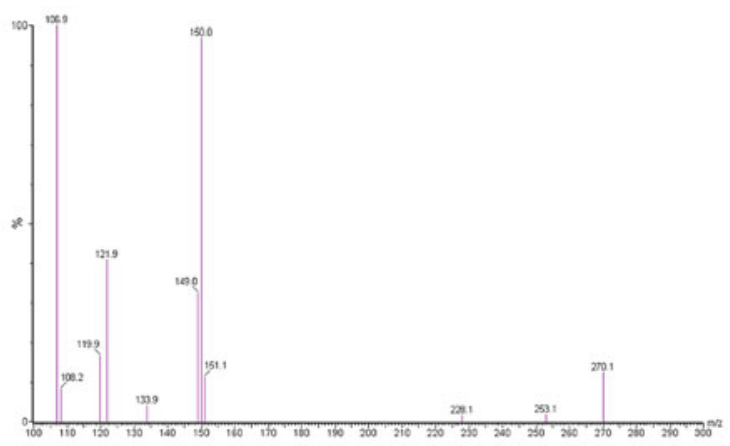

(f) Disperse Yellow 3

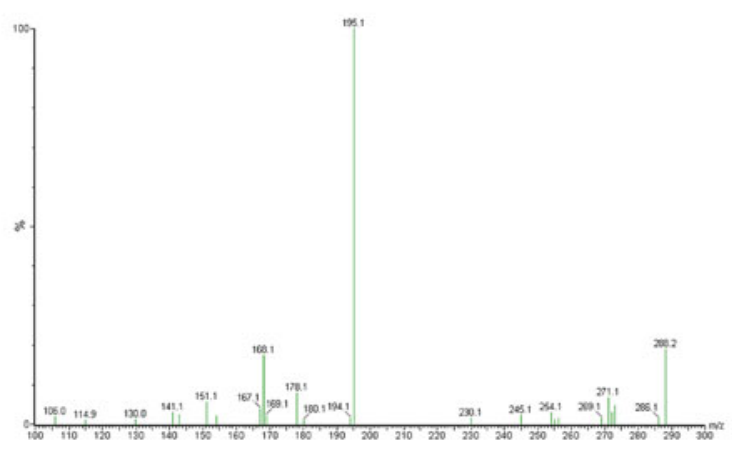

(h) Basic Red 9

Fig. 3. Mass spectra of 16 carcinogenic and allergenic dyestuffs 


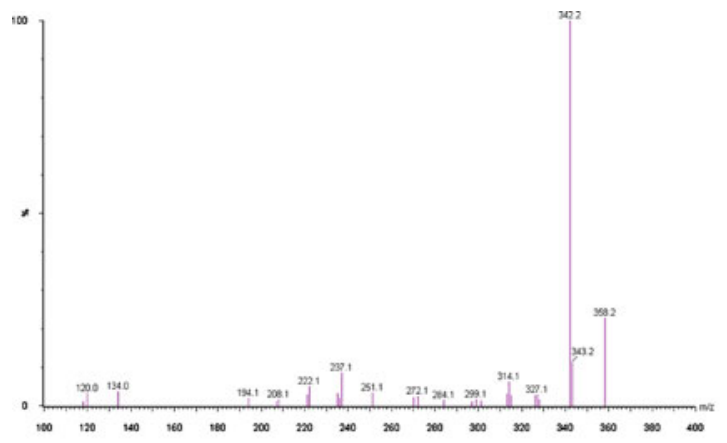

(i) Basic Violet 1

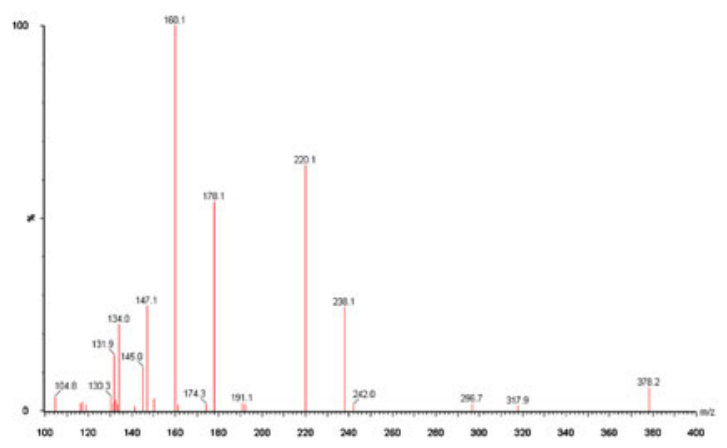

(k) Disperse Blue 124

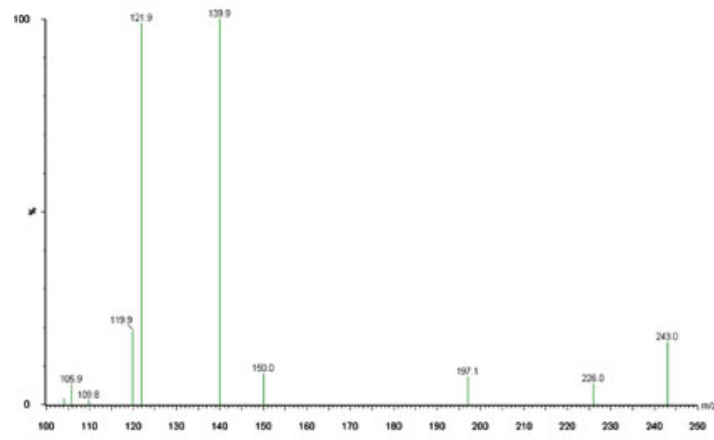

(m) Disperse Orange 3

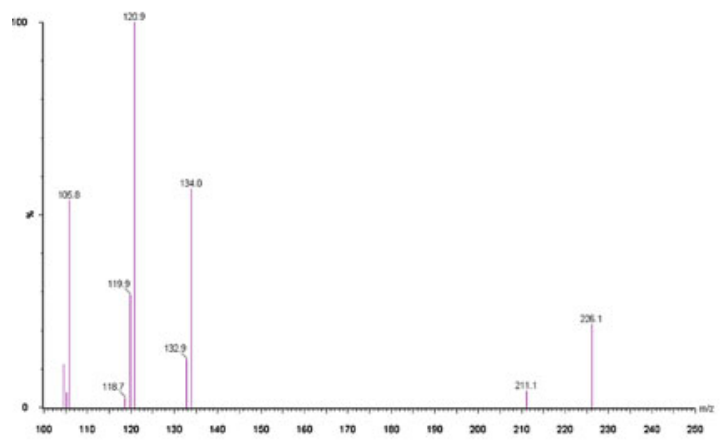

(o) Solvent Yellow 2

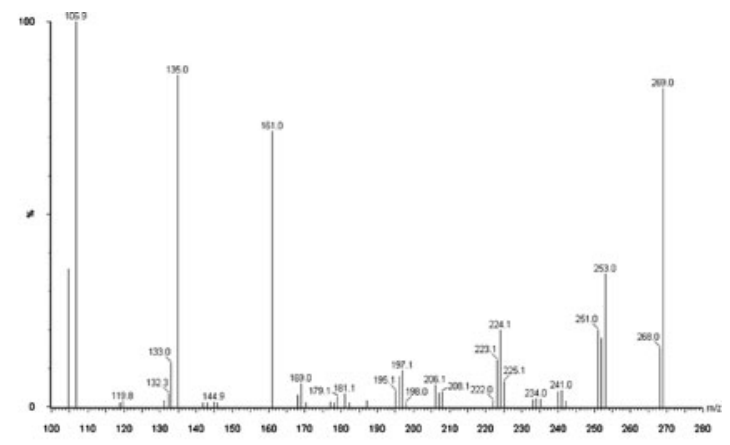

(j) Disperse Blue 1

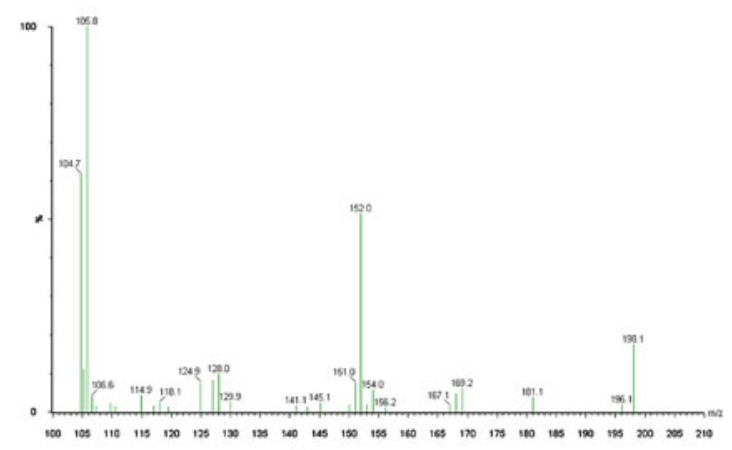

(l) Solvent Yellow 1

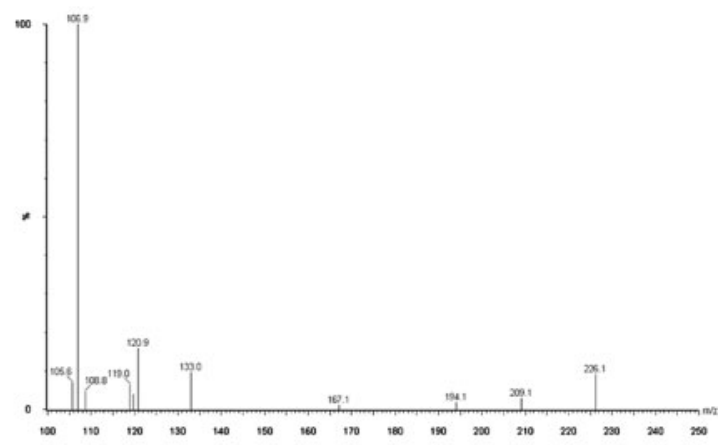

(n) Solvent Yellow 3

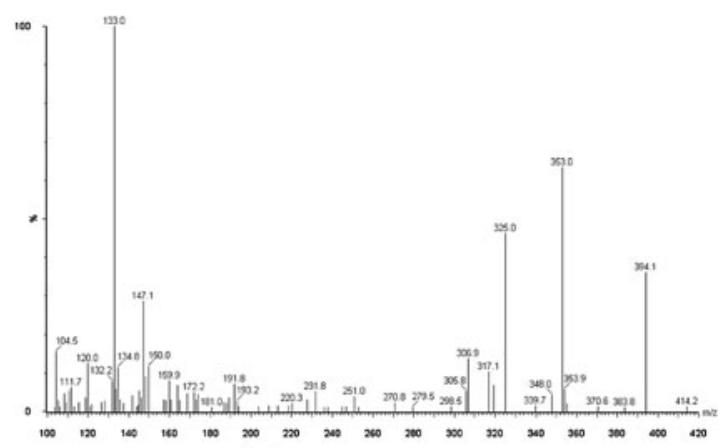

(p) Disperse Orange 37

Fig. 3. continued 
Table 3. Regression equations and correlation coefficients of the developed LC-DAD method

\begin{tabular}{|lll|}
\hline Dyestuffs & Regression equations & Correlation coefficients \\
\hline Basic Violet 3 & $y=217.39 \mathrm{x}-223.44$ & 0.9998 \\
Acid Violet 49 & $y=49.20 \mathrm{x}+38.00$ & 0.9997 \\
Disperse Blue 3 & $y=58.52 \mathrm{x}-42.40$ & 0.9997 \\
Acid Red 26 & $y=49.99 \mathrm{x}+2.41$ & 0.9999 \\
Disperse Blue 106 & $y=49.01 \mathrm{x}-46.89$ & 0.9997 \\
Disperse Yellow 3 & $y=54.18 \mathrm{x}-38.75$ & 0.9997 \\
Disperse Red 1 & $y=151.34 \mathrm{x}-146.32$ & 0.9997 \\
Basic Red 9 & $y=190.71 \mathrm{x}+58.59$ & 0.9994 \\
Basic Violet 1 & $y=154.17 \mathrm{x}-189.25$ & 0.9994 \\
Disperse Blue 1 & $y=19.73 \mathrm{x}+0.79$ & 0.9999 \\
Disperse Blue 124 & $y=48.33 \mathrm{x}-27.32$ & 0.9999 \\
Solvent Yellow 1 & $y=166.07 \mathrm{x}+95.10$ & 0.9992 \\
Disperse Orange 3 & $y=47.15 \mathrm{x}-7.377$ & 0.9999 \\
Solvent Yellow 3 & $y=147.45 \mathrm{x}+13.80$ & 0.9996 \\
Solvent Yellow 2 & $y=164.09 \mathrm{x}-43.24$ & 0.9995 \\
Disperse Orange 37 & $y=39.97 \mathrm{x}-28.90$ & 0.9993 \\
\hline
\end{tabular}

drofuran, were studied. The responses of the mixture reference standard using acetonitrile-water as the mobile phase were observed to be higher than that produced with methanol-water or tetrahydrofuran-water as the mobile phase. Furthermore, mobile phases consisting of acetonitrile paired with different buffer solutions, including $5 \mathrm{mmol} \mathrm{L}^{-1}$ ammonium acetate buffer (adjusted to $\mathrm{pH}$ of $3.75,4.00,4.25,4.50,4.75,5.00$, $5.25, \quad 5.50$ and 5.75 , respectively), $5 \mathrm{mmol} \mathrm{L}{ }^{-1}$ ammonium formate buffer (adjusted to $\mathrm{pH}$ of $2.75,3.00,3.25,3.50$, $3.75,4.00,4.25,4.50$ and 4.75$), 0.1 \%$ acetic acid and $0.1 \%$ formic acid were studied. The comparison revealed that acetonitrile-ammonium acetate $(\mathrm{pH} 5.0)$ achieved the best sensitivity. The ammonium acetate buffer concentrations was varied from 2 to $10 \mathrm{mmol} \mathrm{L}^{-1}$ and this suggested that $5 \mathrm{mmol} \mathrm{L}{ }^{-1}$ was the optimum buffer concentration. There are neither concrete key mass spectrometric parameters, such as parent ions, daughter ions, cone voltages, collision energies, etc., nor spectra for the confirmatory analysis of the sixteen dyestuffs by LCMS-MS provided in EN 71-11, which significantly impaired the practicability and implementation of the standard method. In our study, we systematically developed the LC-MS-MS protocols, with a series of mass spectrometric parameters optimized and specific spectra listed, which thus will help others to follow the experimental procedures.

\section{Method Validation}

The chromatographic protocol was validated for recovery, limits of detection, linear dynamic range and reproducibility. Recoveries at the three spiked levels for different types of toy components, including textiles, leathers, woods, paper, aqueous liquids, solid toy materials intended to leave a trace, modeling or play clay, balloons and temporary tattoos, were evaluated. The observed recoveries were between 88.6 and $104.7 \%$, with the relative standard deviations from 1.6 to $6.7 \%$. In this study, the sample preparation procedure was improved in comparison with EN 71-10 by increasing extraction solvent volume and extraction times to ensure the exhaustive extraction of dyestuffs from toy samples. The linear dynamic range of the LC instrumentation was acquired by analyzing the standard mixture of the sixteen dyestuffs at the concentrations of $1.0,2.0,5.0,10.0,20.0$ and $50.0 \mathrm{mg} \mathrm{L}^{-1}$. Calibration curves were generated using linear regression analysis, giving correlation coefficients above 0.999 over the established range. All the detailed information of the calibration curves are listed in Table 3, and their regression equations were calculated in the form of $y=\mathrm{b} x+\mathrm{a}$, where $y$ and $x$ are the peak area and sample concentration, respectively. The limits of detection for the sixteen dyestuffs with the proposed method, defined as the concentration giving a $\mathrm{S} / \mathrm{N}$ of 3 , were $10 \mathrm{mg} \mathrm{kg}^{-1}$. The intra-day and inter-day reproducibilities were evaluated by injecting a standard mixture five times at three different levels in a single day and during five consecutive days, respectively. The intra-day reproducibility ranged from 1.7 to $3.9 \%$ and inter-day reproducibility ranged from 3.0 to $5.8 \%$.

\section{Analysis of Toy Samples}

Twenty-five toy samples of different categories (textiles, leathers, woods, paper, aqueous liquids, crayons, modeling or play clay, balloons, temporary tattoos, etc.) commercially available from the market were analyzed by the proposed method. The toy samples were subjected to LC-MS-MS confirmatory tests to verify the identification of the analytes. From our investigation, no samples were found containing any of the sixteen carcinogenic and allergenic dyestuffs among the toy samples tested.

\section{Conclusions}

A comprehensive analytical method based on high-performance liquid chromatography coupled with ultraviolet-visible detection and tandem mass spectrometry have been developed for the routine screening analyses of sixteen carcinogenic and allergenic dyestuffs in toys. The chromatographic and mass spectrometric parameters were optimized systematically. The proposed method was evaluated for recovery, limits of detection, linear dynamic range and reproducibility, and shown to be useful for the quality control assay of dyestuffs in various toy products.

\section{Acknowledgments}

This work was supported Quality Inspection Public Welfare Scientific Research Foundation (No. 200810953) and Entry-Exit Inspection and Quarantine Industrial Standard Foundation (No. 2007B265). 


\section{References}

1. BS EN 71-9:2005+A1:2007 Safety of toys. Organic chemical compounds. Requirement. BS EN 71-10:2005 Safety of toys. Organic chemical compounds. Sample preparation and extraction. BS EN 71-11:2005 Safety of toys. Organic chemical compounds. Methods of analysis

2. Öko-Tex Standard 1000, Öko-Tex International, Ausgabe/Edition 01/2009

3. Commission Decision of 9 July 2009 Establishing the ecological criteria for the award of the Community ecolabel for textile products $(2009 / 567 / \mathrm{EC})$

4. Jarosz-Wilkolazka A, KochmanskaRdest J, Malarczyk E, Wardas W,
Leonowicz A (2002) Enzyme Microb Technol 30:566-572. doi:10.1016/ S0141-0229(02)00022-4

5. Scarpi C, Ninci F, Centini M, Anselmi C (1998) J Chromatogr A 796:319-325. doi: 10.1016/S0021-9673(97)01015-7

6. Masukawa Y (2006) J Chromatogr A 1108:140-144. doi:10.1016/j.chroma.2006. 01.007

7. Pérez-Urquiza M, Prat MD, Beltrán JL (2000) J Chromatogr A 871:227-234. doi: 10.1016/S0021-9673(99)01053-5

8. Noguerol-Cal R, López-Vilariño JM, Fernández-Martínez G, Barral-Losada L, González-Rodríguez MV (2008) J Chromatogr A 1179:152-160. doi:10.1016/j. chroma.2007.11.099
9. Garrigós MC, Reche F, Marín ML, Jiménez A (2002) J Chromatogr A 976:309-317. doi:10.1016/S0021-9673(02) 01162-7

10. Ding YC, Xu XH, Sun C, Qian K (2008) Chin J Anal Chem 36:1289-1292

11. Şahin S, Demir C, Güçer Ş (2007) Dyes Pigments 73:368-376. doi:10.1016/j.dyepig. 2006.01.045

12. Commission Decision of 14 August 2002-Implementing council directive 96/ 23/EC concerning the performance of analytical methods and the interpretation of results $(2002 / 657 / \mathrm{EC})$ 